\title{
Treatment of COVID-19-associated ARDS with mesenchymal stromal cells: a multicenter randomized double-blind trial
}

Antoine Monsel ${ }^{1,2,3,23^{*}}$ (D), Caroline Hauw-Berlemont ${ }^{4+}{ }^{+}$Miryam Mebarki ${ }^{5+}$, Nicholas Heming ${ }^{6}$, Julien Mayaux ${ }^{7}$, Otriv Nguekap Tchoumba ${ }^{2,3}$, Jean-Luc Dieh1 ${ }^{4,8}$, Alexandre Demoule ${ }^{7}$, Djillali Annane ${ }^{6}$, Clémence Marois ${ }^{9,10,}$ Sophie Demeret ${ }^{9,10}$, Emmanuel Weiss ${ }^{11,12}$, Guillaume Voiriot ${ }^{13}$, Muriel Fartoukh ${ }^{13}$, Jean-Michel Constantin', Bruno Mégarbane ${ }^{14}$, Gaëtan Plantefève ${ }^{15}$, Stéphanie Malard-Castagnet ${ }^{16}$, Sonia Burrel ${ }^{17}$,

Michelle Rosenzwajg ${ }^{2,3}$, Nicolas Tchitchek ${ }^{2,3}$, Hélène Boucher-Pillet ${ }^{18}$, Guillaume Churlaud ${ }^{18}$, Audrey Cras ${ }^{5,19}$, Camille Maheux ${ }^{18}$, Chloé Pezzana ${ }^{20}$, Mamadou Hassimiou Diallo ${ }^{21}$, Jacques Ropers ${ }^{21}$, Philippe Menasché22†, Jérôme Larghero ${ }^{5,18+}$ and APHP STROMA-CoV-2 Collaborative Research Group

\begin{abstract}
Background: Severe acute respiratory syndrome coronavirus-2 (SARS-CoV-2)-induced acute respiratory distress syndrome (ARDS) causes high mortality. Umbilical cord-derived mesenchymal stromal cells (UC-MSCs) have potentially relevant immune-modulatory properties, whose place in ARDS treatment is not established. This phase $2 \mathrm{~b}$ trial was undertaken to assess the efficacy of UC-MSCs in patients with SARS-CoV-2-induced ARDS.

Methods: This multicentre, double-blind, randomized, placebo-controlled trial (STROMA-CoV-2) recruited adults ( $\geq 18$ years) with SARS-CoV-2-induced early $(<96 \mathrm{~h}$ ) mild-to-severe ARDS in 10 French centres. Patients were randomly assigned to receive three intravenous infusions of $10^{6} \mathrm{UC}-\mathrm{MSCs} / \mathrm{kg}$ or placebo $(0.9 \% \mathrm{NaCl})$ over 5 days after recruitment. For the modified intention-to-treat population, the primary endpoint was the partial pressure of oxygen to fractional inspired oxygen $\left(\mathrm{PaO}_{2} / \mathrm{FiO}_{2}\right)$-ratio change between baseline (day (D) 0 ) and D7.

Results: Among the 107 patients screened for eligibility from April 6, 2020, to October 29, 2020, 45 were enrolled, randomized and analyzed. $\mathrm{PaO}_{2} / \mathrm{FiO}_{2}$ changes between $\mathrm{DO}$ and D7 did not differ significantly between the UC-MSCS and placebo groups (medians [IQR] 54.3 [ -15.5 to 93.3] vs 25.3 [ -33.3 to 104.6], respectively; ANCOVA estimated treatment effect $7.4,95 \% \mathrm{Cl}-44.7$ to 59.7; $P=0.77)$. Six (28.6\%) of the 21 UC-MSCs recipients and six of $24(25 \%)$ placebo-group patients experienced serious adverse events, none of which were related to UC-MSCs treatment.
\end{abstract}

\footnotetext{
*Correspondence: antoine.monsel@gmail.com

${ }^{\dagger}$ Caroline Hauw-Berlemont and Miryam Mebarki contributed equally to

this work and shares co-second authorship

${ }^{\dagger}$ Philippe Menasché and Jérôme Larghero contributed equally to this work and shares last authorship

${ }^{23}$ Multidisciplinary Intensive Care Unit, Department of Anesthesiology-

Critical Care and Perioperative Medicine, Hôpital de la Pitié-Salpêtrière,

47-83, boulevard de l'Hôpital, 75651 Paris Cedex 13, France

Full list of author information is available at the end of the article

Members of the APHP STROMA -CoV-2 Collaborative Research Group are

listed in the Acknowledgments
}

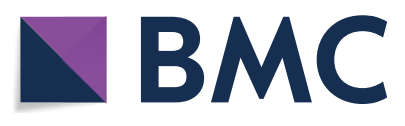

(c) The Author(s) 2022. Open Access This article is licensed under a Creative Commons Attribution 4.0 International License, which permits use, sharing, adaptation, distribution and reproduction in any medium or format, as long as you give appropriate credit to the original author(s) and the source, provide a link to the Creative Commons licence, and indicate if changes were made. The images or other third party material in this article are included in the article's Creative Commons licence, unless indicated otherwise in a credit line to the material. If material is not included in the article's Creative Commons licence and your intended use is not permitted by statutory regulation or exceeds the permitted use, you will need to obtain permission directly from the copyright holder. To view a copy of this licence, visit http://creativecommons.org/licenses/by/4.0/. The Creative Commons Public Domain Dedication waiver (http://creativeco mmons.org/publicdomain/zero/1.0/) applies to the data made available in this article, unless otherwise stated in a credit line to the data. 
Conclusions: D0-to-D7 $\mathrm{PaO}_{2} / \mathrm{FiO}_{2}$ changes for intravenous UC-MSCs-versus placebo-treated adults with SARS-CoV2-induced ARDS did not differ significantly. Repeated UC-MSCs infusions were not associated with any serious adverse events during treatment or thereafter (until D28). Larger trials enrolling patients earlier during the course of their ARDS are needed to further assess UC-MSCs efficacy in this context.

Trial registration: NCT04333368. Registered 01 April 2020, https://clinicaltrials.gov/ct2/history/NCT04333368.

Keywords: Severe acute respiratory syndrome coronavirus-2, Acute respiratory distress syndrome, Umbilical cordderived mesenchymal stromal cells, Good-manufacturing practice

\section{Background}

Severe acute respiratory syndrome coronavirus-2 (SARS-CoV-2) causes coronavirus disease-2019 (COVID-19) and is frequently fatal, with mortality of its most severe forms averaging $30-40 \%$ and necessitating intensive care unit (ICU) admission [1]. A major root cause of those deaths is uncontrolled immune-system dysregulation, leading to, among others, alveolocapillary membrane damage evolving into acute respiratory distress syndrome (ARDS), which requires mechanical ventilation in up to $90 \%$ of ICU patients [2]. One of the hallmarks of COVID-19-associated ARDS is a dysregulated immune response, characterized by a shift of immune cells and their secreted cytokines toward an inflammatory pattern [3]. So far, systemic corticosteroid administration has been shown to lower the 28-day mortality rate of critically-ill COVID-19 patients [3]. Likewise, interleukin (IL)-6-receptor blockers have been reported to improve outcomes (organ-support-free days and survival) [4]. However, the challenges of implementing the vaccination strategy and the emergence of new viral variants still contribute to the persistently high mortality of patients with SARS-CoV-2-induced ARDS [5]. Those findings justify the ongoing quest for new therapies, among which mesenchymal stromal cells (MSCs) are gaining increased interest.

MSCs have well-documented, anti-inflammatory and immune-modulatory properties [6], which have supported their use in treating diseases whose pathophysiologies harbor a major inflammatory component [7]. Specifically, their anti-apoptotic, anti-oxidative, and tissue-reparative properties, diminishing lung vascular and epithelial permeability to proteins, and enhancing clearance of alveolar oedema fluid, have been demonstrated [8]. Furthermore, their capacity to temporarily evade the immune system [9] allows an allogeneic use, which streamlines the logistics of their clinical implementation. In addition, the results of a recent systematic review and meta-analysis of 55 clinical trials demonstrated their satisfactory safety profile [10]. Importantly, MSCs require priming by inflammatory signals to activate their immunomodulatory functions [11], and some of those signals have been shown to be involved in the pathophysiology of
ARDS. Furthermore, their predominant pulmonary lodging following intravenous infusion also argue in favour of administering them to patients with ARDS. As a matter of fact, MSCs have been administered intravenously in phase 1 and 2 clinical trials in more than 150 criticallyill ARDS patients with excellent results in terms of clinical tolerance and even some benefits on the modulation of inflammation biomarkers [12-14]. The combination of those features makes MSCs appealing candidates for treating SARS-CoV-2-induced pulmonary inflammation, as they might have a broader spectrum of action than drugs, which usually have a more limited number of targets. While MSCs can be harvested from various tissue sources, those from the umbilical cord (UC) Wharton's jelly have distinct advantages over bone marrow- or fat tissue-derived MSCs: easy and non-invasive harvesting procedure, good clinical tolerance [15], excellent in vitro scalability and slower time to senescence. Perhaps of greater relevance in the specific context of COVID-19-induced pulmonary damage, UC-MSCs are credited with stronger angiogeneic $[16,17]$ and immunomodulatory properties $[18,19]$. This is well-exemplified by the recent case report of a patient with COVID-19 respiratory failure, who received an intravenously infused of UC-MSCs, and whose in-depth immune profiling of peripheral blood and bronchoalveolar fluid lavage samples revealed: normalization of the circulating T-lymphocytes count, and reductions of inflammatory myeloid cells, serum levels of proinflammatory cytokines and lung-infiltrating inflammatory neutrophils, while circulating monocytes and low-density gradient neutrophils acquired immunosuppressive functions [20]. These UC-MSCs characteristics, possibly attributable to their more primitive origin compared with adult tissue-derived MSCs [18], might explain why those of cord origin were the most widely used according to a recent review of registered trials testing MSCs in COVID-19 patients [21]. In the specific context of SARS-CoV-2-induced severe ARDS, another reason for using UC-MSCs, is that they do not express the angiotensin-converting enzyme-2 receptor [22], unlike MSCs originating from other tissue types [23].

Studies testing UC-MSCs in COVID-19 patients published so far have consisted of anecdotal case reports 
[24, 25], small-sized non-randomized or open-label studies [22, 26-29] and only two recent, single-centre, double-blind, placebo-controlled trials [30, 31]. Overall, those studies' results confirmed the excellent tolerance of intravenous MSC infusions and suggested improved clinical outcomes, although their interpretation is complicated by the broad heterogeneity of patients' pre-treatment profiles, therapeutic doses and timing of treatment administration, cell tissue source, the different passage numbers at which cells were collected and the diversity of additional treatments, which generate strong background noise. We therefore designed this multicentre, doubleblind, randomized, placebo-controlled STROMA-CoV-2 trial was designed to determine whether repeated intravenous infusions of UC-MSCs derived from Wharton's jelly during the early stage of SARS-CoV-2-related ARDS could improve its resolution and impact circulating levels of biomarkers.

\section{Methods}

A detailed description of the methods and the full clinical trial protocol are provided in the Additional file 1.

\section{Study design}

The multicentre, double-blind, randomized, placebo-controlled STROMA-CoV-2 trial was designed to compare the intravenous infusion of UC-MSCs versus saline placebo as add-on therapy for the management of SARS$\mathrm{CoV}$-2-induced ARDS. The study was conducted in ten ICUs in eight French university hospitals. The National Review Board of Île-de-France III approved the trial (CNRIPH 20.03.26.39722) that was authorized by the French National Agency for Medicines and Health Products Safety (EudraCT 2020-001287-28). The trial is registered with ClinicalTrals.gov identifier NCT04333368. A
Data-Safety-Monitoring Board reviewed serious adverse events and the results after 10, 20 and 40 patients had been enrolled.

\section{Patients}

Eligible patients had Berlin criteria-defined ARDS (mildto-severe) for $<96 \mathrm{~h}$, reverse transcriptase-polymerase chain reaction (RT-PCR)-confirmed SARS-CoV-2 infection, and were receiving respiratory support (invasive or non-invasive mechanical ventilation, and/or high-flow nasal oxygenation, with positive end-expiratory pressure equivalent $\geq 5 \mathrm{cmH}_{2} \mathrm{O}$ ). Patients with pulmonary embolism, immunocompromised status, liver disease, chronic lung disease or cancer were excluded. The detailed list of exclusion criteria is given in Table 1 . Written informed consent was obtained from patients or a legally designated representative.

\section{Randomization and blinding}

Subjects were initially randomized at a 1:2 ratio to receive either the total dose of $3 \times 10^{6} \mathrm{UC}-\mathrm{MSCs} / \mathrm{kg}$ in $150 \mathrm{~mL}$ of $0.9 \% \mathrm{NaCl} / 0.5 \%$ albumin or placebo $(150 \mathrm{~mL}$ of $0.9 \%$ $\mathrm{NaCl}$ ) over 5 days, which was modified by a protocol amendment to 1:1 when patients became scarce at the end of the first wave. Randomization was stratified according to age ( $\leq 70$ vs $>70$ years) and the inclusionday (D0) Sequential Organ-Failure Assessment (SOFA) score $(\leq 11 \mathrm{vs}>11)$. All healthcare providers and patients were unaware of treatment assignment; only cell-production-unit staff members were not blinded.

\section{Production of the UC-MSCs-based advanced therapy medicinal product}

The study treatments (UC-MSCs or placebo) were prepared by the Cell Therapy Unit and the MEARY Cell

Table 1 Inclusion and exclusion criteria

Inclusion criteria
Age $>18$ years
Reverse transcriptase-polymerase chain reaction -confirmed SARS-CoV-2
infection
Berlin criteria-defined acute respiratory distress syndrome for $<96 \mathrm{~h}$
Respiratory support (invasive or non-invasive mechanical ventilation, and/
or high-flow nasal oxygenation) with positive end-expiratory pressure
equivalent $\geq 5 \mathrm{~cm} \mathrm{H}_{2} \mathrm{O}$

\section{Exclusion criteria}

Age $<18$ years

Acute respiratory distress syndrome present for $>96 \mathrm{~h}$

Pulmonary fibrosis

Pulmonary hypertension (WHO classification class III or IV)

Pulmonary embolism within the previous 3 months

Extracorporeal membrane oxygenation or life support

Immunocompromised status including use of immunosuppressive medi-

cations

Pregnancy or breastfeeding

Treatment for cancer in the past 2 years

Underlying medical condition with life expectancy $<6$ months

Moderate-to-severe liver disease (Child-Pugh score $>12$ )

Severe chronic lung disease with the use of home oxygen and/or partial

arterial pressure of carbon dioxide $>50 \mathrm{~mm} \mathrm{Hg}$

Patients not committed to full support (i.e., had do not resuscitate or limit

life support orders)

Participation in another trial of COVID-19 therapeutics 
and Gene Therapy Center, which are two adjacent buildings, located in the same hospital (Saint Louis Hospital, Paris, France). Briefly, the investigational advanced therapy medicinal product was a suspension of allogenic UC-MSCs, isolated from human UC Wharton's jelly by enzymatic digestion or the explant method, and amplified in vitro. Quality controls (Additional file 1: Table S1, S2 and S3) included viability, identity, purity, functionality (clonogenicity, immunosuppressive effects) and safety (microbiological, endotoxin and mycoplasma assays; karyotype).

\section{Procedures}

Each patient received three intravenous infusions of $10^{6}$ UC-MSCs $/ \mathrm{kg}$ (maximum dose set at $80 \times 10^{6}$ cells per infusion) or placebo on D1, D3 \pm 1 and D $5 \pm 1$. All patients were monitored for any changes of pre-specified respiratory or cardiovascular parameters (see Additional file 1) and were ventilated according to the modified ARDS Network lower tidal volume protocol. Management of ARDS, septic shock and other organ failures followed international guidelines [32, 33].

\section{Clinical and biological outcomes}

The primary endpoint of the study was respiratory improvement assessed as the partial pressure of oxygen to fractional inspired oxygen $\left(\mathrm{PaO}_{2} / \mathrm{FiO}_{2}\right)$-ratio change between baseline (D0) and D7 post-randomization. Secondary and safety endpoints are provided in the Additional file 1. To assess UC-MSCs biological activity, biomarkers of endothelial, alveolar epithelial injury and inflammation were measured in plasma obtained on D0, D2, D4, D7, and D14, as exploratory endpoints. SARS-CoV-2 nucleocapsid antigenemia (N-antigenemia) and viral RNA levels were measured in plasma on D1 and D7. The level of donor-specific anti-human leucocyte antigen (HLA) antibodies (DSAs) directed against UC-MSCs was also measured on D0 and D14 to detect allo-immunization.

\section{Statistical analyses}

Continuous data are expressed as mean \pm standard deviation or median [interquartile range, IQR]. Categorical parameters are expressed as numbers (percentages).

The primary endpoint was the evolution of the $\mathrm{PaO}_{2} /$ $\mathrm{FiO}_{2}$ ratio between $\mathrm{D} 0$ and $\mathrm{D} 7 . \mathrm{PaO} 2 / \mathrm{FiO} 2$ ratios of patients who died were imputed to 50 , considered a minimum possible value. Given the lack of literature data available at the time, the last observation carried forward (LOCF) plus $10 \%$ imputation for the missing $\mathrm{PaO}_{2} / \mathrm{FiO}_{2}$ ratios of patients who improved and were discharged from the ICU seemed reasonable and consistent with their clinically observed recovery dynamics. A sensitivity analysis was computed using a LOCF approach. The mean difference between the two groups was compared using analysis of covariance (ANCOVA), adjusting for the D0 $\mathrm{PaO}_{2} / \mathrm{FiO}_{2}$ ratio and stratification factors. Wilcoxon rank-sum test was used to analyse robustness. Statistical analyses used a two-sided $5 \%$ threshold of significance.

The principal analysis was conducted according to modified intent-to-treat, including all randomized patients, except those who received no dose of the assigned treatment. A per-protocol analysis was also conducted on patients who had received the three planned doses of the assigned treatment.

The evolutions of the criteria of interest were analysed at different times. Simple comparisons used Student's, Wilcoxon's, $x^{2}$, or Fisher's exact tests according to the type of data. The evolution of clinical criteria, especially respiratory, was subjected to longitudinal modeling. Random-effects models were used to take into account a subject's repeated measurements. Biomarkers were $\log _{10}$-transformed before analysis. Left-censoring (values below the limit of quantification) was accounted for either by modeling or imputation using each biomarker's half-value of the limit of quantification. In light of the exploratory nature of the study, no penalty for the multiplicity of comparisons was implemented, except for cytokines that were subjected to Benjamini-Hochberg correction.

The sample size was chosen pragmatically in consideration of the capacity to produce UC-MSCs during a period when the need was urgent. However, the simulation run, which was meant to be only illustrative, suggested that the study should be able to demonstrate a $50 \% \mathrm{PaO}_{2} /$ $\mathrm{FiO}_{2}$-ratio increase from D0 to D7, based on the first information available on the $\mathrm{PaO}_{2} / \mathrm{FiO}_{2}$-ratio distributions of COVID-19 patients in ICUs.

All analyses and calculations were computed using $\mathrm{R}$ software version 4.0.3, R Core Team (2020), R Foundation for Statistical Computing, Vienna, Austria.

\section{Results}

\section{Patients}

Patients were enrolled from April 6, 2020, to October 29,2020 , in the ICUs at ten study sites. Among the 107 patients screened for eligibility, 47 were randomly assigned to a treatment group and 45 received either UCMSCs $(n=21)$ or placebo $(n=24$; Fig. 1$)$. Their demographic characteristics are reported in Table 2. ARDS was mild, moderate or severe, respectively, in $31.1 \%$, $48.9 \%$ and $20 \%$ of the patients. While SOFA and lung injury scores, and $\mathrm{PaO}_{2} / \mathrm{FiO}_{2}$ ratio were similar for the two groups, more placebo-group patients were on invasive mechanical ventilation, receiving vasopressors and neuromuscular blocking agents. Fifteen (71.4\%) and 19 


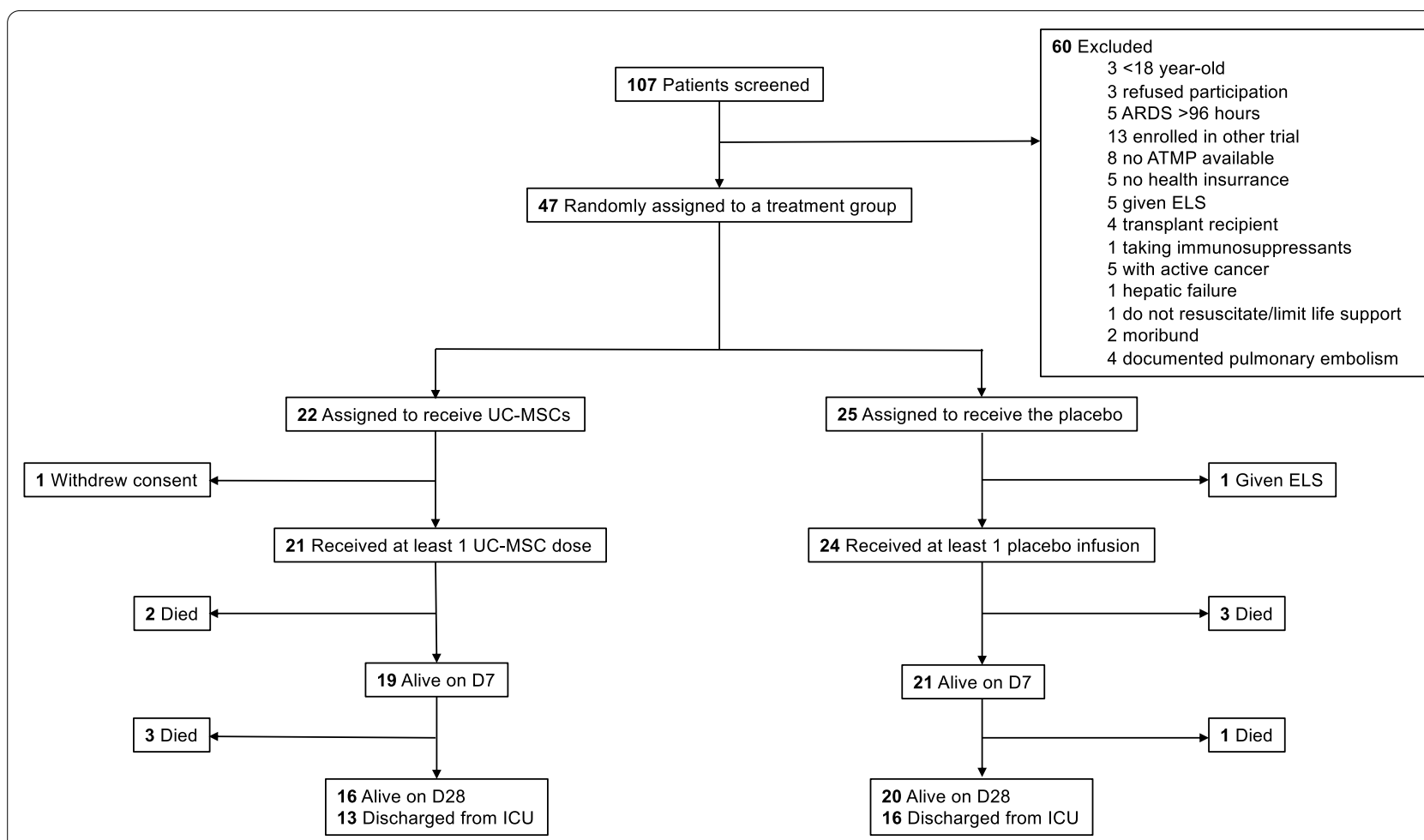

Fig. 1 Flowchart of the trial. ARDS acute respiratory distress syndrome. ATMP advanced therapeutic medicinal product. D day. ELS extracorporeal life support. ICU intensive care unit. UC-MSCS umbilical cord-derived mesenchymal stromal cells

(79.2\%) patients in the UC-MSC and placebo groups, respectively, received corticosteroids during the first 7 days (Table 3). During the first 28 days, the two groups had similar respiratory characteristics (Additional file 1: Table S4).

\section{Treatment}

During the 5-day treatment period, $81.0 \%, 9.5 \%$ and 9.5\% of UC-MSC recipients received three, two and one cell infusions, respectively (Table 3 ); they received a mean of $0.9 \pm 0.1 \times 10^{6} \mathrm{UC}-\mathrm{MSCs} / \mathrm{kg}$ per dose (range $0.6-1 \times 10^{6} \mathrm{UC}-\mathrm{MSCs} / \mathrm{kg}$ ) (Additional file 1: Table S5). Two (4\%) UC-MSC batches did not meet specifications because of insufficient cell counts $\left(<1.00 \pm 0.1 \times 10^{6} /\right.$ $\mathrm{kg}$ ) (Additional file 1: Table S5). Cell viability was $78.4 \pm 5.3 \%$ and consistent across all batches ( $\geq 70 \%)$ (Additional file 1: Tables S2 and S3). UC-MSCs expressed CD90 (99.2 $\pm 1.6 \%)$, CD73 (99.9 $\pm 0.1 \%)$, and CD105 (97.0 $\pm 1.9 \%)$, while CD45, CD34, CD11b, CD19, and HLA-DR $(0.8 \pm 0.7 \%)$ were below their defined positivity thresholds (2\%). The colony-forming unit-fibroblast assay yielded a frequency of $1.8 \pm 1.1 \%$ and all batches satisfied the $>1 \%$ specification. Mixed lymphocyte-reaction assays, run to confirm UC-MSC immunomodulatory properties, showed significant dose-dependent inhibition of T-cell proliferation, with a peak inhibitory rate of
$86 \pm 5 \%$ for a UC-MSC/peripheral blood mononuclear cell ratio of $1: 1$.

\section{Primary endpoint}

Of the 21 and 24 patients randomized to the UC-MSC and placebo groups, respectively, 17 and 18 of them had D7 primary endpoint measurements available. The respective numbers of patients whose D7 $\mathrm{PaO}_{2} / \mathrm{FiO}_{2}$ ratio values had to be imputed were four (three discharged and one died) and six (five discharged and one died). The primary outcome measure $\left(\mathrm{PaO}_{2} / \mathrm{FiO}_{2}\right.$-ratio change between D0 and D7 post-randomization) did not differ significantly between the UC-MSC and placebo groups (median imputed values: 54.3 [IQR -15.5 to 93.3] vs 25.3 [IQR -33.3 to 104.6 ], respectively; ANCOVA treatment-effect estimate $7.4,95 \%$ CI -44.7 to 59.7 ; $P=0.77$, Table 4).

Sensitivity, per-protocol, and subgroup analyses (Additional file 1: Table S6) showed similar results.

Although the $\mathrm{D} 0 \mathrm{PaO}_{2} / \mathrm{FiO}_{2}$ ratios for the two groups were similar (Fig. 2A), the UC-MSC group's ratio increased significantly from D0 to D7 (156.2 \pm 68.2 vs $188.3 \pm 74.2$, respectively; $P=0.03$ ) for the subgroup of patients remaining alive in the ICU over the first 7 days (Fig. 2B), but the numerical difference was no longer significant according to the post-imputation analysis 
Table 2 Patients' baseline characteristics

\begin{tabular}{|c|c|c|c|}
\hline & UC-MSC $(n=21)$ & Placebo $(n=24)$ & $p$ value \\
\hline Age, years & $64(10.4)$ & $63.2(11.4)$ & 0.82 \\
\hline Male sex & 17 (81\%) & $20(83.3 \%)$ & 1 \\
\hline Body mass index & $28.6(3.5)$ & $28(5.5)$ & 0.68 \\
\hline Obesity & $7(33.3 \%)$ & $6(25 \%)$ & 0.54 \\
\hline Sepsis-related Organ-Failure Assessment score & $5.5(2.7)$ & $5.9(2.7)$ & 0.64 \\
\hline Mean arterial pressure, $\mathrm{mm} \mathrm{Hg}$ & $91.3(18.3)$ & $81.5(16.9)$ & 0.07 \\
\hline On vasopressors & $5(23.8 \%)$ & $14(58.3 \%)$ & 0.02 \\
\hline \multicolumn{4}{|l|}{ Comorbidities } \\
\hline Chronic obstructive pulmonary disease & $0(0 \%)$ & $1 / 15(6.7 \%)$ & 1 \\
\hline Active smoking & $0(0 \%)$ & $0(0 \%)$ & 0.24 \\
\hline Chronic heart failure & $0(0 \%)$ & $0(0 \%)$ & 1 \\
\hline Atrial fibrillation & 2/15 (13.3\%) & $0(0 \%)$ & 0.21 \\
\hline Hypertension & $11 / 15(73.3 \%)$ & 10/15 (66.7\%) & 0.47 \\
\hline Coronary artery disease & 2/15 (13.3\%) & 2/15 (13.3\%) & 1 \\
\hline Stroke & 2/15 (13.3\%) & $1 / 15(6.7 \%)$ & 0.59 \\
\hline Immunodeficiency & $0(0 \%)$ & $0(0 \%)$ & 1 \\
\hline Active neoplasia & $0(0 \%)$ & $0(0 \%)$ & 1 \\
\hline Chronic corticosteroid intake & $0(0 \%)$ & $0(0 \%)$ & 1 \\
\hline Immunomodulatory drugs & 2/17 (11.8\%) & $0(0 \%)$ & 0.2 \\
\hline \multicolumn{4}{|l|}{ Respiratory characteristics } \\
\hline Ventilatory support (NIV and/or HFNO) & $10(47.6 \%)$ & $4(16.7 \%)$ & 0.02 \\
\hline Invasive mechanical ventilation & $11(52.4 \%)$ & $20(83.3 \%)$ & 0.02 \\
\hline Tidal volume, $\mathrm{mL} / \mathrm{kg}$ PBW & $6.2(0.7, n=11)$ & $6.3(0.8, n=20)$ & 0.72 \\
\hline Plateau airway pressure, $\mathrm{cm} \mathrm{H}_{2} \mathrm{O}$ & $21.8(4.2, n=10)$ & $24.8(5.1, n=17)$ & 0.12 \\
\hline PEEP & $10.8(2.9, n=11)$ & $11.2(3.2, n=20)$ & 0.72 \\
\hline Driving pressure & $11.3(4.3, n=10)$ & $13.2(3.9, n=17)$ & 0.25 \\
\hline Compliance, $\mathrm{mL} / \mathrm{cm} \mathrm{H}_{2} \mathrm{O}$ & $45.2(27.8, n=10)$ & $35.2(14.9, n=17)$ & 0.29 \\
\hline $\mathrm{SpO}_{2}, \%$ & $94.6(3.4)$ & $96.0(3.0, n=23)$ & 0.16 \\
\hline $\mathrm{PaO}_{2} / \mathrm{FiO}_{2}, \mathrm{~mm} \mathrm{Hg}$ & $156.2(68.2)$ & $171.2(72.9)$ & 0.53 \\
\hline Lung injury score & $3.0(0.7)$ & $2.8(0.5)$ & 0.61 \\
\hline $\mathrm{PaCO}_{2}, \mathrm{~mm} \mathrm{Hg}$ & $40(8.5)$ & $43.2(9.8)$ & 0.17 \\
\hline $\mathrm{pH}$ & $7.41(0.1)$ & $7.37(0.1)$ & 0.27 \\
\hline Neuromuscular blocking agents & $6(28.6 \%)$ & $16(66.7 \%)$ & 0.01 \\
\hline \multicolumn{4}{|l|}{ Ventilation mode } \\
\hline Volume control & $11 / 11(100 \%)$ & 19/20 (95\%) & 1 \\
\hline Pressure control & $0(0 \%)$ & $0(0 \%)$ & 1 \\
\hline Pressure support & $0(0 \%)$ & $1 / 20(5 \%)$ & 1 \\
\hline
\end{tabular}

Values are expressed as mean (standard deviation) or number (\%). Information was available for all patients, unless indicated otherwise

HFNO high-flow nasal oxygen therapy, $\mathrm{NIV}$ non-invasive ventilation, $\mathrm{PaCO}_{2}$ partial pressure of arterial carbon dioxide, $\mathrm{PaO}_{2} / \mathrm{FiO}_{2}$ ratio of partial pressure of oxygen to fractional inspired oxygen, $P B W$ predicted body weight, $P E E P$ positive end-expiratory pressure, $\mathrm{SpO}_{2}$ peripheral capillary oxygen saturation, UC-MSCS umbilical cordderived mesenchymal stromal cells

(156.2 \pm 68.2 vs $194.7 \pm 95.3$, respectively; $P=0.08)$. In contrast, the placebo group's $\mathrm{PaO}_{2} / \mathrm{FiO}_{2}$ ratio remained unchanged from D0 to D7.

\section{Secondary endpoints}

No significant between-group secondary-endpoint differences were observed for SOFA scores, $\mathrm{PaO}_{2} / \mathrm{FiO}_{2}$ ratios, compliance, driving pressure change between D0 and D7 or D14, organ-failure-free days, ventilation-free days, duration of ventilation, time to weaning, time to ICU discharge, time to reach $\mathrm{PaO}_{2} / \mathrm{FiO}_{2}>200$ or $>300$, and mortality to D28 (Table 4 and Additional file 2: Figure S1).

Before and after D14, the numbers of adverse events, serious adverse events, and patients with any adverse 
Table 3 Assigned treatment doses received and corticosteroid administration from day 0 to day 7

\begin{tabular}{llc}
\hline & UC-MSCs $(\boldsymbol{n}=\mathbf{2 1})$ & Placebo $(\boldsymbol{n}=\mathbf{2 4})$ \\
\hline $\begin{array}{l}\text { Number of doses } \\
\text { received over } 7 \text { days }\end{array}$ & $2.7(0.6)$ & $2.7(0.5)$ \\
$\quad$ & $2(9.5 \%)$ & $1(4.2 \%)$ \\
One & $2(9.5 \%)$ & $4(16.7 \%)$ \\
$\quad$ Thro & $17(81 \%)$ & $19(79.2 \%)$ \\
Corticosteroids & $15(71.4 \%)$ & $19(79.2 \%)$ \\
administered for & & \\
7 days & &
\end{tabular}

Values are expressed as number (\%)

UC-MSCs umbilical cord-derived mesenchymal stromal cells

and/or any serious adverse events were similar for the two groups (Table 5, Additional file 1: Table S7). In total, $36(80 \%)$ patients experienced adverse events prior to D14, and 18 (40\%) thereafter. The vast majority of adverse events were considered to be related to COVID-19 progression. Only one UC-MSC-group patient experienced an adverse event (diarrhoea) deemed possibly related to the study treatment. Only one placebo patient suffered a pre-specified adverse hemodynamic event within $6 \mathrm{~h}$ of infusion onset (Additional file 1: Table S8). Six (28.6\%) UC-MSC recipients had pre-formed DSA, i.e., present before treatment and directed against the HLA of the infused UC-MSCs received. On D14, three (14.3\%) patients had synthesized de novo low-level DSA. Eleven (45.8\%) placebo recipients had performed anti-HLA, and no patient developed de novo significant anti-HLA immunization between D0 and D14.

Inflammatory biomarker-analysis (Additional file 3: Figures S2 and Additional file 4: Figure S3) and plasma virus-load results (Additional file 5: Figure S4) are reported in Additional file 1. Later decreases of inflammatory markers in the UC-MSC-treated group were the

Table 4 Main clinical outcomes

\begin{tabular}{|c|c|c|c|c|}
\hline Primary endpoint & UC-MSCs $(n=21)$ & Placebo $(n=24)$ & Estimate $(95 \% \mathrm{Cl})$ & $p$ value \\
\hline $\begin{array}{l}\mathrm{PaO}_{2} / \mathrm{FiO}_{2} \text {-ratio change D0-D7(principal } \\
\text { analysis) }\end{array}$ & $54.3[-15.5 ; 93.3]$ & $25.3[-33.3 ; 104.6]$ & $7.4(-44.7 ; 59.7)$ & 0.77 \\
\hline $\begin{array}{l}\mathrm{PaO}_{2} / \mathrm{FiO}_{2} \text {-ratio change D0-D7(sensitivity } \\
\text { analysis) }\end{array}$ & $54.3[-15.5 ; 93.3]$ & $25.3[-33.3 ; 83.1]$ & $12.5(-33.8 ; 56.7)$ & 0.59 \\
\hline Secondary endpoints & UC-MSCs $(n=21)$ & Placebo $(n=24)$ & $\begin{array}{l}\text { Median difference }(95 \% \mathrm{Cl}) \text {, } \\
\text { HR or sub-HR }\end{array}$ & $p$ value \\
\hline $\mathrm{PaO}_{2} / \mathrm{FiO}_{2}$-ratio change D0-D14 & $11.0[-39 ; 72.7]$ & $28.2[-1 ; 67.3]$ & $1.69(-82.1 ; 90.7)$ & 1 \\
\hline Ventilation-free days to D28, $n$ & $17.0[0 ; 25.0]$ & $12.0[0 ; 19.7]$ & $0.5(-3.0 ; 8.0)$ & 0.61 \\
\hline Ventilation duration to $D 28, n$ & $9.0[3.0 ; 20.0]$ & $10[5.7 ; 20.0]$ & $-2.5(-8.0 ; 3.0)$ & 0.38 \\
\hline $\begin{array}{l}\text { Ventilation duration to D28 for recipients } \\
\text { of } 3 \text { UC-MSC doses }\end{array}$ & $11.0[6.0 ; 24.0]$ & $13.0[7.0 ; 22.0]$ & $-0.5(-8 ; 6)$ & 0.79 \\
\hline SOFA-score change D0-D7 & $-1.5[-2 ; 0.75]$ & $-2[-3.2 ; 0.2]$ & $0.5(-2.0 ; 3.0)$ & 0.60 \\
\hline SOFA-score change D0-D14 & $-0.5[-1.2 ; 1.0]$ & $-3.0[-3 ;-1.0]$ & $1.5(-1.0 ; 5.0)$ & 0.12 \\
\hline Organ-failure-free days to D $14, n$ & $3.0[0 ; 6.0]$ & $2.0[0 ; 9.0]$ & $-0.5(-4.0 ; 3.0)$ & 0.96 \\
\hline Organ-failure-free days to $D 28, n$ & $16.0[2.0 ; 20.0]$ & $15.0[0.75 ; 23]$ & $-0.5(-7.0 ; 4.0)$ & 0.68 \\
\hline Days to reach $\mathrm{PaO}_{2} / \mathrm{FiO}_{2}>200$ & $5.0[0 ; 16.0]$ & $2.5[0 ; 6.5]$ & $0.74[0.3 ; 1.6]$ & 0.44 \\
\hline Days to reach $\mathrm{PaO}_{2} / \mathrm{FiO}_{2}>300$ & $12.0[7.0 ; 23.0]$ & $15.0[5.0 ; 27.0]$ & $1.1[0.5 ; 2.3]$ & 0.87 \\
\hline Days to ICU discharge ${ }^{a}$ & $15.0[8.0 ; \mathrm{NA}]$ & $13.0[5.5 ; 27]$ & $0.8[0.4 ; 1.7]$ & 0.59 \\
\hline Days to weaning ${ }^{b}$ & $13.0[9.0 ; \mathrm{NA}]$ & $17.0[8.0 ; \mathrm{NA}]$ & $1.3[0.5 ; 3.3]$ & 0.55 \\
\hline Compliance change D0-D7 & $-3.6[-11.8 ; 4.7]$ & $-0.1[-4.5 ; 2.4]$ & $0.4(-24.7 ; 25.5)$ & 1 \\
\hline Compliance change D0-D14 & $-3.0[-3.0 ;-3.0]$ & $2.5[-0.9 ; 11.7]$ & $-5.52(-35.4 ; 1.1)$ & 0.8 \\
\hline Driving pressure change D0-D7 & $0.5[-3.2 ; 4.2]$ & $0.5[-1.2 ; 2.2]$ & $0(-13.0 ; 13.0)$ & 1 \\
\hline Driving pressure change D0-D14 & $1.0[1.0 ; 1.0]$ & $-1.5[-2.0 ; 0.2]$ & $2.5(-3.0 ; 3.0)$ & 0.8 \\
\hline D28 mortality & $5.0(26.3 \%)$ & $4.0(18.2 \%)$ & $2.0(0.5 ; 8.5)$ & 0.36 \\
\hline
\end{tabular}

Values are expressed as median [interquartile range], or number (\%), unless stated otherwise

$\mathrm{Cl}$ confidence interval, $\mathrm{D}$ day, $\mathrm{HR}$ hazard ratio, $I \mathrm{CU}$ intensive care unit, $\mathrm{NA}$ not applicable, $\mathrm{PaO}_{2} / \mathrm{FiO}_{2}$ ratio of partial pressure of oxygen to fractional inspired oxygen, PEEP positive end-expiratory pressure, SOFA Sepsis-related Organ-Failure Assessment, UC-MSCs umbilical cord-derived mesenchymal stromal cells

${ }^{\text {a }}$ Censored at day of death for patients having died before D28 and censored at D28 for those patients still in the ICU at D28

${ }^{b}$ Estimated for the subgroup of patients ventilated at randomization, i.e., 31 patients (11 in CSM-CO group and 20 in placebo group). At Day 28,6 had died (and censored at time of death), 17 were weaned, and 8 were alive and not weaned yet (censored at D28) 


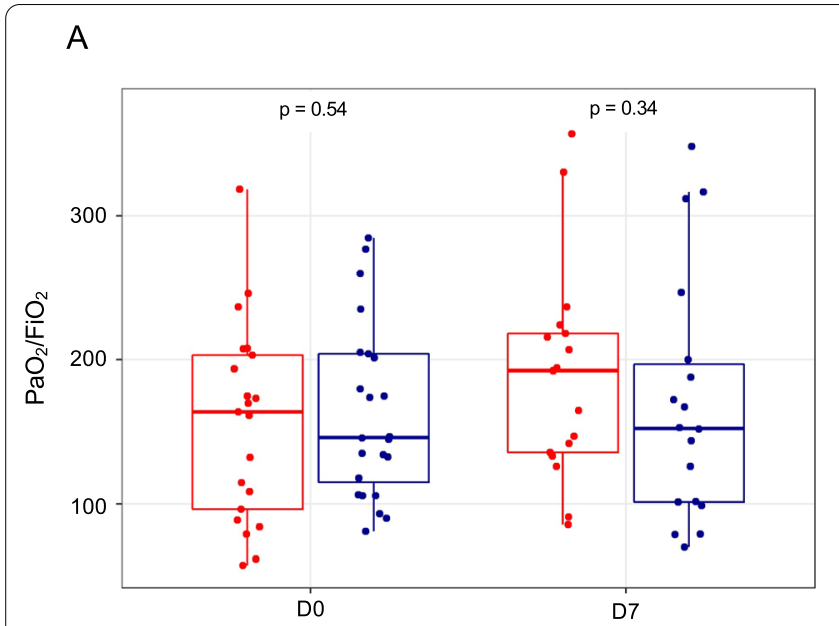

B

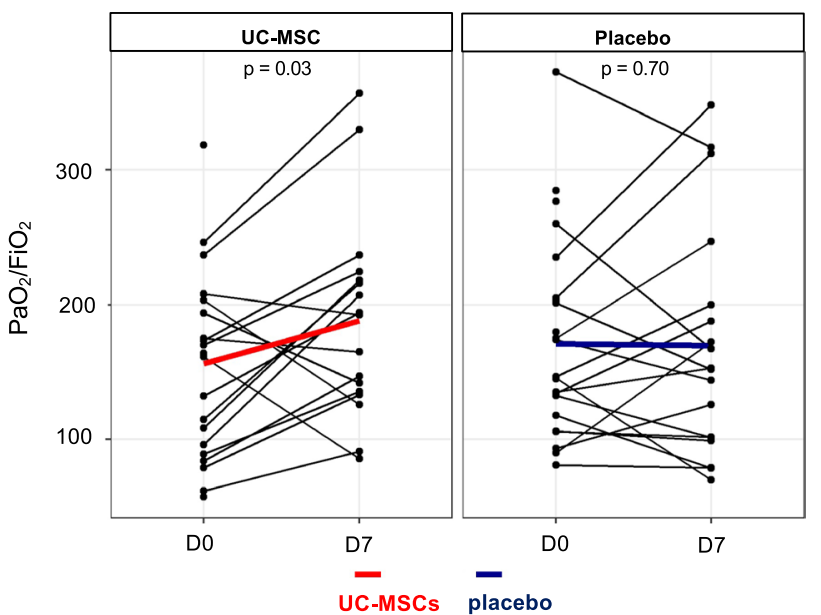

Fig. 2 Primary endpoint: $\mathrm{PaO}_{2} / \mathrm{FiO}_{2}$ values and their changes between days 0 and 7. A Baseline (D0) and $\mathrm{D} 7 \mathrm{PaO}_{2} / \mathrm{FiO}_{2}$ ratios were similar for the two groups. Box plots of $\mathrm{PaO}_{2} / \mathrm{FiO}_{2}$ ratios: internal horizontal lines are the medians; lower and upper box limits are the 25th-75th interquartile range, respectively; and vertical bars represent the 10th and 90th percentiles. $\mathbf{B ~} \mathrm{PaO}_{2} / \mathrm{FiO}_{2}$ ratios increased significantly from D0 to D7 in the UC-MSC group (respectively, $156.2 \pm 68.2$ vs $188.3 \pm 74.2$; Wilcoxon signed-rank exact test). The placebo group's $\mathrm{PaO}_{2} / \mathrm{FiO}_{2}$ ratios on D0 and D7 were comparable (respectively, $171.2 \pm 72.9$ vs $169.8 \pm 85.6$, Wilcoxon signed-rank exact test). UC-MSCs group in red; placebo group in blue. $\mathrm{D}$ day. $\mathrm{PaO} / / \mathrm{FiO} 2$ ratio of partial pressure of oxygen to fractional inspired oxygen. UC-MSCs umbilical cord-derived mesenchymal stromal cells

only significant difference found (Additional file 3: Figure S2).

\section{Discussion}

The main finding of this study is that repeated intravenous infusions of UC-MSCs into patients with SARSCoV-2-induced early ARDS were safe, but did not improve oxygenation, as reflected by the $\mathrm{PaO}_{2} / \mathrm{FiO}_{2}$-ratio change between D0 and D7, compared to the placebo group.

Two randomized trials have previously tested UCMSCs in COVID-19 patients [30]. Whereas the study by Lanzoni et al. [30] included patients with ARDS and/ or hypoxemia with $\mathrm{SpO} 2<94 \%$, the patients enrolled by Dilogo et al. [31] were those with leukopenia and severe COVID-19 pneumonia, without further specification. Although the percentage of patients on invasive mechanical ventilation at inclusion was given in one study [30], neither of the two studies reported the distribution of invasively ventilated patients and their differences in UC-MSC and placebo groups, either at baseline or during follow-up. While the majority of patients described by Lanzoni et al. were also receiving adjuvant treatments administered at inclusion (i.e., remdesivir, convalescent plasma, tocilizumab, corticosteroids or hydroxychloroquine), this information was not given in the second study [31]. Finally, while the MSC-administration scheme consisted of two infusions of 100 million cells at day D0 and D3 for the former study, the latter administered one million $/ \mathrm{kg}$ in a single infusion given between $\mathrm{D} 2$ and D30. The number of cell passages before use was not indicated in either study.

Our double-blind, randomized, placebo-controlled trial has several other key strengths, including serial determinations of a wide array of inflammation and immunity-related biomarkers at several times until D14, monitoring of allo-immunization, and thorough characterization of the final UC-MSC-based product. Instead of assessing the three-lineage differentiation of our cells, we rather used a potency assay more specific for their intended immunomodulatory effect and to this end performed mixed lymphocyte reactions which confirmed their inhibitory effect on allogeneic T lymphocytes [34]. A final key strength is the multicenter design. However, the small number of patients included in ten centers over 6 months has several origins: (1) the pandemic dynamics were in successive waves, with periods of acceleration and deceleration of patient flows; (2) many patients admitted to the ICU were already included in phase 2 or 3 therapeutic trials, precluding inclusion in our trial; (3) some patients could not be included because of the unavailability of the manufacturing cell therapy unit. For the future, scaling up MSC production made possible by current technologies should allow to cover the needs of large numbers of patients.

A second important finding is that repeated UC-MSC infusions were not associated with any serious adverse events during treatment or thereafter (until D28). More 
Table 5 Summary of the 139 reported adverse events occurring in the 24 UC-MSC- and 21 placebo-treated patients

\begin{tabular}{|c|c|c|c|c|}
\hline & UC-MSC & Placebo & Total & $p$ value \\
\hline \multicolumn{5}{|l|}{ Adverse events D0-D14 } \\
\hline Subjects with AEs & 18/21 (85.7\%) & $18 / 24(75 \%)$ & $36 / 45(80 \%)$ & 0.47 \\
\hline AEs reported & $49 / 97(50.5 \%)$ & $48 / 97(49.5 \%)$ & $97(100 \%)$ & 0.29 \\
\hline Subjects with SAEs & $6 / 21(28.6 \%)$ & $6 / 24(25 \%)$ & $12 / 45(26.7 \%)$ & 0.79 \\
\hline SAEs reported & $10 / 49(20.4 \%)$ & $6 / 48(12.5 \%)$ & $16 / 97(16.5 \%)$ & 0.29 \\
\hline AEs by severity & & & & 0.99 \\
\hline Mild & $16 / 49(32.7 \%)$ & 15/48 (31.3\%) & $31 / 97(32 \%)$ & \\
\hline Moderate & $24 / 49(49 \%)$ & $24 / 48(50 \%)$ & $48 / 97(49.5)$ & \\
\hline Severe & $9 / 49(18.4 \%)$ & 9/48 (18.7\%) & 18/97 (18.6) & \\
\hline AE grade ${ }^{a}$ & & & & 0.14 \\
\hline Grade 1 & $19 / 47(40.4 \%)$ & 10/48 (20.8\%) & 29/95 (30.5\%) & \\
\hline Grade 2 & 15/47 (31.9\%) & 19/48 (39.6\%) & $34 / 95(35.8 \%)$ & \\
\hline Grade 3 & 9/47 (19.1\%) & $16 / 48(33.3 \%)$ & $25 / 95(26.3 \%)$ & \\
\hline Grade 4 & $4 / 47(12.5 \%)$ & $3 / 48(6.3 \%)$ & $7 / 95(7.4 \%)$ & \\
\hline AEs by treatment relatedness & & & & 0.41 \\
\hline Possible & $1 / 48(2.1 \%)^{b}$ & $0(0 \%)$ & $1 / 95(1.1 \%)$ & \\
\hline Other treatment & $4 / 48(8.3 \%)$ & $2 / 47(4.3 \%)$ & $6 / 95(6.3 \%)$ & \\
\hline Other disease & $1 / 48(2.1 \%)$ & $1 / 47(2.1 \%)$ & $2 / 95(2.1 \%)$ & \\
\hline COVID-19 progression & $28 / 48(58.3 \%)$ & $37 / 47(78.7 \%)$ & $65 / 95(68.4 \%)$ & \\
\hline Other causes & $3 / 48(6.3 \%)$ & $2 / 47(4.3 \%)$ & $5 / 95(5.3 \%)$ & \\
\hline Undetermined & $11 / 48(22.9 \%)$ & $5 / 47(10.6 \%)$ & 16/95 (16.8\%) & \\
\hline \multicolumn{5}{|l|}{ Adverse events after D14 } \\
\hline Subjects with AEs & $9 / 21(38.1 \%)$ & $9 / 24(37.5 \%)$ & $18 / 45(40 \%)$ & 0.71 \\
\hline AEs reported & 19/42 (45.2\%) & 23/42 (54.8\%) & $42(100 \%)$ & 1.00 \\
\hline Subjects with SAEs & $4 / 21(19 \%)$ & $4 / 24(16.7 \%)$ & $8 / 45(17.8 \%)$ & 1.00 \\
\hline SAEs reported & $4 / 19(21.1 \%)$ & $4 / 23(17.4 \%)$ & $8 / 42(19 \%)$ & 1.00 \\
\hline AEs by severity & & & & 0.19 \\
\hline Mild & $7 / 19(36.8 \%)$ & $3 / 23(13 \%)$ & $10 / 42(23.8 \%)$ & \\
\hline Moderate & $7 / 19(36.8 \%)$ & $12 / 23(52.2 \%)$ & 19/42 (45.2\%) & \\
\hline Severe & $5 / 19(26.3 \%)$ & $8 / 23(34.8 \%)$ & $13 / 42(31 \%)$ & \\
\hline AE grade ${ }^{a}$ & & & & 0.18 \\
\hline Grade 1 & $7 / 18(38.9 \%)$ & $3 / 23(13 \%)$ & $10 / 41(24.4 \%)$ & \\
\hline Grade 2 & $7 / 18(38.9 \%)$ & $15 / 23(65.2 \%)$ & $22 / 41(53.7 \%)$ & \\
\hline Grade 3 & $1 / 18(5.6 \%)$ & $3 / 23(1 \%)$ & 4/41 (9.8\%) & \\
\hline Grade 4 & $3 / 18(16.7 \%)$ & $2 / 23(8.7 \%)$ & $5 / 41(12.2 \%)$ & \\
\hline AEs by treatment relatedness & & & & 0.54 \\
\hline Possible & $0(0 \%)$ & $0(0 \%)$ & $0(0.0 \%)$ & \\
\hline Other treatment & $3 / 14(21.4 \%)$ & $4 / 20(20 \%)$ & $7 / 34(20.6 \%)$ & \\
\hline Other disease & $1 / 14(7.1 \%)$ & $0(0 \%)$ & $1 / 34(2.9 \%)$ & \\
\hline COVID-19 progression & $8 / 14(57.1 \%)$ & $11 / 20(55 \%)$ & 19/34 (55.9\%) & \\
\hline Other causes & $2 / 14(14.3 \%)$ & $2 / 20(10 \%)$ & $4 / 34(11.8 \%)$ & \\
\hline Undetermined & $0(0 \%)$ & $3 / 20(15 \%)$ & $3 / 34(8.8 \%)$ & \\
\hline
\end{tabular}

Values are expressed as number (\%). AEs adverse events. SAEs severe adverse events. UC-MSC umbilical cord-derived mesenchymal stromal cells

a Grade from the Common Terminology Criteria for Adverse Events classification

${ }^{\mathrm{b}}$ Possible non-serious treatment-related AE: diarrhoea

specifically, data collected from continuous hemodynamic and respiratory monitoring during intravenous infusion of UC-MSC suggested good clinical tolerance during UC-MSC administration, with no transfusion incompatibility or infusion-related events. MSCs have already been used to treat a wide variety of diseases 
without safety issues, but those results might not be directly applicable to COVID-19, because one of the disease's hallmark is the potential for pulmonary thrombotic microangiopathy, which could have been worsened by UC-MSCs obstructing the pulmonary capillary bed, thereby causing right heart failure. No such event was documented in our trial. At least three factors might have contributed to the good tolerance of UC-MSC infusions: 1) when MSCs are cultured in 5\% humanplatelet lysate and for no longer than 3-4 passages, as in our trial, the reported cell size (in suspension) had been $\sim 17 \mu \mathrm{m}$, which should keep cells within the safety range in terms of risk of vascular obstruction [35]; (2) the intrinsic prothrombotic activity of UC-MSCs is mitigated by intermediate-level anticoagulation administration, now recommended and widely given to hospitalized COVID-19 patients [2], and it is reassuring that SCD40L levels, known to increase coagulation, were not elevated in UC-MSC-treated patients compared with controls (data not shown); and (3) the rapid apoptotic fragmentation of intravenously delivered UC-MSCs that became trapped in lung tissue and underwent progressive size diminution [36], and subsequent phagocytosis of apoptotic fragments by monocytes and neutrophils [37] could have contributed further to cell clearance from the vascular bed. Finally, it is noteworthy that only three of the UC-MSC-treated patients developed allo-immunization to the infused cells and their mean fluorescence intensity (MFI) values were in the low range, unlikely to be cell-damaging [38]. That finding is consistent with previously reported clinical study results documenting the low immunogenicity of UC-MSCs [39].

Concerning efficacy, the trial did not meet its primary endpoint, since $\mathrm{PaO}_{2} / \mathrm{FiO}_{2}$-ratio changes between D0 and D7 did not differ significantly between UC-MSCand placebo-infused patients. First, this lack of difference might suggest that, when COVID-19-associated respiratory failure is severe enough to warrant invasive mechanical ventilation or ventilatory support, the extent of lung damage outweighs the effects of UC-MSCs, at least when delivered according to the dosing schedule used herein, and thus their capacity to promote lung-tissue repair translating into improved oxygenation patterns. That lack of efficacy contrasts with the spectacularly improved survival obtained in two previous trials [30,31] that applied a similar double-blind, randomized design. However, in those studies, control-group mortality was unusually high (50\% [31] to $58 \%$ [30] vs $21.9 \%$ herein), which allowed room for clearer demonstration of treatment effects. Furthermore, in both studies, although invasively ventilated patients were included, their distributions in each group were not specified; severity scores were missing and the timing of UC-MSC administration in relation to the ARDS stage (early or late) was either focused on the early [30] or the resolution phase (i.e., $>7$ days) of ARDS [31], thereby making comparisons between the studies difficult. Second, the presence of pre-formed and de novo DSA in six (28.6\%) and three (14.3\%) UC-MSC-treated patients, respectively, might have altered therapeutic efficacy by accelerating MSC clearance, but this is unlikely because these patients' MFI levels were low-to-moderate and, except for one, remained below the 5,000 threshold level beyond which DSA-HLA-1 MFIs correlate with complement-dependent and antibody-dependent cellmediated cytotoxicities [40]. The choice of the primary endpoint is a third possible explanation. The absence of $\mathrm{FiO}_{2}$ or positioning (supine or prone) standardization for measuring $\mathrm{PaO}_{2} / \mathrm{FiO}_{2}$ might have increased the variability of its values from D0 to D7 [41], thereby hindering a beneficial or deleterious effect evaluated in the study. Moreover, some authors have questioned the prognostic value of $\mathrm{PaO}_{2} / \mathrm{FiO}_{2}$ in ARDS patients [42]. The $\mathrm{PaO}_{2} /$ $\mathrm{FiO}_{2}$ ratio has several limitations [43]: (1) it does not reflect the ventilation applied and does not account for mean airway pressure or positive end-expiratory pressure; (2) it is dependent on barometric pressure; (3) it cannot distinguish hypoxemia due to alveolar hypoventilation from other causes, such as ventilation-perfusion mismatch and shunt; (4) it is markedly dependent on $\mathrm{FiO}_{2}$; (5) it is highly dependent on oxygen extraction capacity; (6) it does not indicate oxygen content of the blood, or oxygen delivery to tissues. On the other hand, the study was designed at the very beginning of the first French pandemic wave, in February 2020, and, at that time, locally available data (from several ICUs in Paris) suggested a potentially notable improvement of survivors' gas exchange on D7 (no published or quantified data available at that time). Therefore, we decided to use the day- $7 \mathrm{PaO}_{2} / \mathrm{FiO}_{2}$ ratio as the primary endpoint. Another hypothesis explaining the absence of therapeutic effects is a potential lack of power of the study. Indeed, most phase 2 studies on ARDS had wide confidence intervals that, most often, limited generalizability [44]. Thus, our finding that the UC-MSC-group's-but not the placebo group's- $\mathrm{PaO}_{2} / \mathrm{FiO}_{2}$ ratio rose significantly from D0 to D7 might have reflected some treatment efficacy that remained too modest to emerge with our sample size. However, this observation must be balanced against the fact that: (1) the numerical increase of the UC-MSC group's- $\mathrm{PaO}_{2} / \mathrm{FiO}_{2}$ ratio from D0 to D7 was no longer significant following the post-imputation analysis, and (2) more placebo-group patients were invasively ventilated, under vasopressors and neuromuscular blocking agents, thereby indicating greater disease severity and potentially favoring the treated group. 
Concerning circulating biomarker-level changes, it remains unclear whether the UC-MSC group's later appearance of the proinflammatory cytokine- and chemokine-level declines is a signature of the treatment, potentially leading to any benefit in terms of inflammation resolution. Results of previous randomized-controlled studies showed either a trend [31] or a significant immunoregulatory effect [30], with UC-MSC-treated patients having marked reductions of several circulating inflammatory biomarkers from D0 to D6-D7. Those heterogeneous findings can probably be explained by the differences in therapeutic doses, timing, choices of biomarkers to be measured and the small numbers of patients included, but also by the fact that those marker levels were determined in plasma and not the alveolar compartment. Indeed, Wick et al. recently found the MSC immunomodulatory effect in non-COVID-19 patients with ARDS to be more detectable in bronchoalveolar lavage at $48 \mathrm{~h}$ post-MSC administration than in blood [45]. In future studies exploring the immunomodulatory impact of MSCs in patients with COVID-19-associated ARDS, it will probably also be important to measure these markers at early time points post-infusion and in bronchoalveolar lavage, if feasible.

We acknowledge that the STROMA-CoV-2 trial has limitations. They include the small sample size and the lack of a robust sample-size calculation explained by the paucity of published data at that time on the distribution and kinetics of $\mathrm{PaO}_{2} / \mathrm{FiO}_{2}$ ratio in this patient population; the likely patient-management modifications clearly illustrated by an almost systematic use of corticosteroids during the second wave of the pandemic, with the caveat that, although in vitro study results indicated a generic cytotoxic effect of these drugs on MSCs, dexamethasone, which has been the gold standard during the pandemic (and was used in our trial), is the one with the least harmful effects on cell viability [46]; the higher percentage of invasively ventilated placebo-group patients on neuromuscular blocking agents and vasopressors, probably explained in part by the randomization-ratio change introduced between the 1st and 2nd pandemic waves, may have favored the treated group. However, the inclusion SOFA score, lung injury score, and $\mathrm{PaO}_{2} / \mathrm{FiO}_{2}$ ratio were comparable for the two groups; potential differences might exist in the bioactivities of the infused cells, despite quality-control consistency between the first and second batches, derived from 2 distinct donors; and the dosing and timing of delivery schedule are still debated. Indeed, the UC-MSC doses used have varied across studies, with a median dose of 100 million for intravenous delivery and a minimal effective dose ranging from 70 to 190 million/patient/dose [47]. Furthermore, although we are not aware of any comparison of a total aggregate dose given as a single bolus versus its fractionation over time, the rapid UC-MSC clearance led us to adopt repeated dosing, in hopes of inducing a longer-term effect. Those considerations rationalized our choice of three $1 \times 10^{6}$ UC-MSCs $/ \mathrm{kg} /$ dose repeated every other day, a dosing strategy consistent with several of the registered cell-therapy trials on COVID-19 patients [48]. However, it remains to be assessed whether outcomes can be improved by higher doses and/or longer time intervals between cell deliveries.

\section{Conclusions}

The results of this phase $2 \mathrm{~b}$, multicentre, double-blind, randomized, placebo-controlled trial showed no efficacy of human UC-MSCs on the $\mathrm{PaO}_{2} / \mathrm{FiO}_{2}$-ratio change between D0 and D7 in patients with SARS-CoV-2-induced ARDS compared to placebo. D28 mortality also did not differ. Despite the lack of statistically significant differences, UC-MSC-treated patients' greater $\mathrm{PaO}_{2} /$ $\mathrm{FiO}_{2}$-ratio increase between D0 and D7, compared to placebo-infused controls, might represent a signal warranting further investigation on a larger patient population. Repeated UC-MSC infusions were not associated with any serious adverse events during treatment or thereafter (until D28). Consequently, to better assess in which direction this treatment strategy shifts the risk-benefit and cost-effectiveness balances, pursuit of this avenue of research on COVID-19-associated pneumonia would be notably enhanced by greater homogeneity of patient demographics and standardized therapeutic protocols, reappraisal of the most clinically relevant endpoints and larger sample sizes.

\section{Abbreviations}

ANCOVA: Analysis of covariance; ARDS: Acute respiratory distress syndrome; CFU: Colony-forming unit; COVID-19: Coronavirus disease-2019; D: Day; DSAs: Donor-specific anti-human leukocyte antigen antibodies; $\mathrm{PaO}_{2} / \mathrm{FiO}_{2}$ : Partial pressure of oxygen to fractional inspired oxygen; HLA: Human leukocytes antigen; ICU: Intensive care unit; L: Interleukin; IQR: Interquartile range; LOCF: Last Observation Carried Forward; MFI: Mean fluorescence intensity; MSCs: Mesenchymal stromal cells; RT-PCR: Reverse transcriptase-polymerase chain reaction; SARS-COV-2: Severe acute respiratory syndrome coronavirus-2; SOFA: Sequential Organ-Failure Assessment; UC: Umbilical cord.

\section{Supplementary Information}

The online version contains supplementary material available at https://doi. org/10.1186/s13054-022-03930-4.

Additional file 1: A detailed description of the methods and the full clinical trial protocol. Table S1. Quality-control characteristics of UC-MSCS used as treatment: identity and safety. Table S2. Quality-control characteristics of batch-1 UC-MSCs used as treatment: identity and safety. Table S3. Quality-control characteristics of batch-2 UC-MSCs used as treatment: identity and safety. Table S4. Evolution of respiratory characteristics from baseline (D0) to D28 Table S5. UC-MSCs posology per patient. Table S6. 
Subgroup analyses of the primary outcome. Table S7. Complete list of adverse events. Table S8. Summary of pre-specified infusion-associated adverse events for randomized subjects.

Additional file 2: Figure S1. Survival probabilities and SOFA scores. (A) Survival rates from D0 to D28 were comparable for the two groups ( $P=0.63$, log-rank test). (B) SOFA-score evolutions from D0 to D28 did not differ $(P=0.79$, Wilcoxon test). Data are expressed as mean per day \pm standard deviation. D day. SOFA Sequential Organ-Failure Assessment score. UC-MSCs umbilical cord-derived mesenchymal stromal cells.

Additional file 3: Figure S2. Analysis of plasma inflammatory cytokines, chemokines, growth factors, and biomarkers at baseline (D0) and D2, D4, D7, and D14 after starting infusions. Concentrations of 48 cytokines were quantified in plasma from UC-MSC- $(n=20)$ or placebo- treated $(n=21)$ patients. Statistical analyses with Wilcoxon rank-sum tests compared values between groups ( $A$ ) and within each group ( $B$ and $C$ ) at each day indicated. Volcano plots were generated for each comparison to show the $\log _{2}$ fold-changes relative to placebo or D0, with statistical significance reported as $-\log _{10} P$-values. Significance, defined as $P<0.05$, is in blue, with those remaining statistically significant after multiple corrections (Benjamini-Hochberg correction) in red D day, DO baseline, UC-MSC umbilical cord-derived mesenchymal stromal cell, ANGP-1 angiopoietin-1, $B C A-1$ B-cell-attracting chemokine-1, CTACK cutaneous T-cell-attracting chemokine, CXCL-9 chemokine (C-X-C motif) ligand 9, EGF epidermal growth factor, FLT-3L Fms-related tyrosine kinase-3 ligand, G-CSF granulocyte-colony-stimulating factor, IFN- $\gamma$ interferon- $\gamma$, IL interleukin, IP-10 interferon gamma-induced protein-10, $M C P$ monocyte chemoattractant protein, M-CSF macrophage-colony-stimulating factor, MDC macrophagederived chemokine, PDGF-AA platelet-derived growth factor-AA, RAGE receptor for advanced glycation end products, SCD $40 \mathrm{~L}$ soluble cluster of differentiation-40 ligand, SDF stromal cell-derived factor, SPD surfactant protein B, TGF- $a$ transforming growth factor- $a$, TPO thrombopoietin, VEGF$A$ vascular endothelial growth factor-A.

Additional file 4: Figure S3. Analysis of plasma inflammatory cytokine, chemokine, growth factor, and biomarker concentrations on D0 (baseline), D2, D4, D7, and D14 after starting infusions. The figure reports the quantification results for 10 cytokines selected among the 48 sought in plasma samples from patients treated with UC-MSCs $(n=20)$ or placebo $(n=21)$ Data are $\log _{2}$ transformed. Box plots of $\mathrm{PaO}_{2} / \mathrm{FiO}_{2}$ ratios: internal horizontal lines are the medians, lower and upper box limits are the 25 th and 75 th interquartile range, respectively, vertical bars are drawn down to the 10th percentile and up to the 90th percentile. D day, IL interleukin. IP-10 interferon-gamma-induced protein-10, MCP monocyte chemoattractant protein, RAGE receptor for advanced glycation end products, SDF-1 stromal cell-derived factor-a, UC-MSCS umbilical cord-derived mesenchymal stromal cells.

Additional file 5: Figure S4. Analysis of plasma SARS-CoV-2 RNA and $\mathrm{N}$-antigenemia levels at baseline (D0) and D2, D4, D7, and D14 after starting infusions. Plasma SARS-CoV-2 RNA (by RT-PCR) and N-antigenemia in UC-MSC- $(n=21$, red) or placebo-treated $(n=24$, blue) patients were quantified. Based on viral RNA levels (A), five (23.8\%) UC-MSC- and eight (33.3\%) placebo-treated patients had detectable viremia on D0, while (B) $\mathrm{N}$-antigenemia was positive for 20 (95.2\%) and 22 (91.7\%) patients, respectively. (C) Plasma SARS-CoV-2 NAg-level change from D0 to D14. Data are expressed as mean \pm standard deviation. The percentage of viremic patients and $\mathrm{N}$-antigenemia levels decreased sharply until D4 (A-C). No between-group difference was observed in terms of percentage of viremic patients and/or decline from D0 to D14. Red=UC-MSC group; blue $=$ placebo group. $D$ day, $\mathrm{PaO}_{2} / \mathrm{FiO}_{2}$ ratio of partial pressure of oxygen to fractional inspired oxygen, RT-PCR reverse transcription-polymerase chain reaction, SARS-COV-2 severe acute respiratory syndrome coronavirus-2, UC-MSCs umbilical cord-derived mesenchymal stromal cells.

\section{Acknowledgements}

Members of the AP-HP STROMA-CoV-2 Collaborative Research Group are: Déborah Benchetrit, Harold Bonvallot, Fanny Charbonnier-Beaupel, Meriem Dhib-Charfi, Pierre Romain Delmotte, Assitan Kone, Marine Le Corre, AnneGeneviève Marcelin, Carole Metz, Louis Puybasset, Joe-Elie Salem, Corinne
Vezinet. We thank Sophie Sayon and Karen Zafilaza for technical assistance concerning the SARS-CoV-2 nucleocapsid-antigenemia and viral RNA-level determinations. We also thank APHP (Delegation of Clinical Research and Innovations (DRCI).

\section{Authors' contributions}

$\mathrm{AM}, \mathrm{PM}$, JL, and JR contributed to overall study design and developed the protocol. AM, CH, JM, ONT, JLD, AD, NH, DA, CM, SD, EW, CP, GV, MF, JMC, BM, JES, and GP were responsible for study enrolment, data collection, and manuscript editing. MM, AC, HB, CM, GC, and JL were responsible for manufacturing the experimental drug and preparing the placebo. AM, ONT, MR, PM, AC, and MM were responsible for biorepository management, biomarker analyses, and interpretation. NT was responsible for statistical analyses of biomarker data. JR and MHD were responsible for statistical analyses of clinical data. AM, PM, JR, $A C, M M, S M, S B, M R, O N T$, and JL contributed to the data analysis and manuscript writing. All authors read and approved the final manuscript.

\section{Funding}

This study was funded by the French Ministry of Health (Programme Hospitalier de Recherche Clinique National COVID-19 2020) and by the French National Research Agency (ANR Flash COVID-19). The funder of the study had no role in the study design, data collection, data analysis, data interpretation, or writing of this report. The corresponding author had full access to all the study data and had final responsibility for the decision to submit for publication.

\section{Availability of data and materials}

Qualified clinical researchers can request access to de-identified participant dataset, informed consent forms and related documents, including the study protocol that underlie this article through submission of a proposal with a valuable research question to the corresponding author, subject to agreement of a contract.

\section{Declarations}

\section{Ethics approval and consent to participate}

The National Review Board of Île-de-France III approved the trial (CNRIPH 20.03.26.39722) that was authorized by the French National Agency for Medicines and Health Products Safety (EudraCT 2020-001287-28). Written informed consent was obtained from patients or a legally designated representative.

\section{Consent for publication}

Not applicable.

\section{Competing interests}

AD declared grants or contracts from Philips, Fisher \& Paykel; French Ministry of Health; Respinor; Lungspacer; consulting fees from Lungspacer, Respinor; payments or honoraria for lectures, presentations, speaker bureaus, manuscript writing or educational events from Fisher \& Paykel, Getinge, Lungspacer, Gilead, Lowenstein, Astra; support for attending meetings and/or travel from Fisher \& Paykel, Lungspacer; received equipment, materials, drugs, medical writing, gifts or other services from Lungspacer, Respinor. MF declared grants or contracts from BioMérieux and MSD; French Ministry of Health; consulting fees from Pfizer; payments or honoraria for lectures, presentations, speaker bureaus, manuscript writing or educational events from Fisher \& Paykel and Biomérieux; participation on a data safety monitoring board or advisory board. ONT received grants or contracts from the French National Society of Internal Medicine (SNFMI). No conflict of interests is reported for other authors.

\section{Author details}

${ }^{1}$ Multidisciplinary Intensive Care Unit, Department of Anesthesiology and Critical Care, La Pitié-Salpêtrière Hospital, Assistance Publique-Hôpitaux de Paris (APHP) Sorbonne University, Paris, France. ${ }^{2}$ Sorbonne UniversitéINSERM UMRS_959, Immunology-Immunopathology-Immunotherapy (I3), 75013 Paris, France. ${ }^{3}$ Biotherapy (CIC-BTi), Hôpital Pitié-Sal pêtrière, APHP, 75651 Paris, France. ${ }^{4}$ Intensive Care Unit, APHP-CUP, Hôpital Européen Georges-Pompidou, Université de Paris, 75015 Paris, France. ${ }^{5}$ APHP, Hôpital Saint-Louis, Unité de Thérapie Cellulaire, Centre d'Investigation Clinique en Biothérapies CBT501, INSERM, Université de Paris, Paris, France. ${ }^{6}$ FHU SEPSIS, Department of Intensive Care, Hôpital Raymond-Poincaré (APHP), Laboratory 
of Infection \& Inflammation-INSERM U1173, Simone Veil School of Medicine, University Versailles Saint Quentin-University Paris Saclay, 92380 Garches, France. ${ }^{7}$ APHP, Groupe Hospitalier Universitaire-Sorbonne Université, site Pitié-Salpêtrière, Service de Médecine Intensive et Réanimation (Département R3S), and Sorbonne Université, INSERM, UMRS1 158 Neurophysiologie Respiratoire Expérimentale et Clinique, Paris, France. ${ }^{8}$ Innovative Therapies in Hemostasis, INSERM, 75006 Paris, France, and Biosurgical Research Laboratory (Carpentier Foundation), APHP-CUP, Hôpital Européen Georges-Pompidou, Université de Paris, 75015 Paris, France. ${ }^{9}$ Neurological Intensive Care Unit, Department of Neurology, La Pitié-Salpêtrière Hospital, APHP, Sorbonne University, Paris, France. ${ }^{10}$ Groupe de Recherche Clinique en REanimation et Soins intensifs du Patient en Insuffisance Respiratoire aiguE (GRC-RESPIRE), Sorbonne Université, Paris, France. ${ }^{11}$ Department of Anesthesiology and Critical Care, Beaujon Hospital, DMU PARABOL, APHP Nord, Paris, France. ${ }^{12}$ Center for Research on Inflammation, INSERM and Université de Paris, Paris, France. ${ }^{13}$ Service de Médecine Intensive Réanimation, Hôpital Tenon, APHP, Sorbonne Université, Paris, France. ${ }^{14}$ Department of Medical and Toxicological Critical Care, Lariboisière Hospital, INSERM UMRS1144, University of Paris, Paris, France. ${ }^{15}$ Service de Réanimation Polyvalente, Centre Hospitalier Victor Dupouy, 69, Rue du Lieutenant-Colonel Prud'hon, 95100 Argenteuil, France. ${ }^{16} \mathrm{Immunology}$ and HLA Laboratory, Hôpital Saint-Louis, Paris, France. ${ }^{17}$ INSERM U1136, Institut Pierre-Louis d'Epidémiologie et de Santé Publique (iPLESP), APHP, Hôpital Pitié-Salpêtrière, Service de Virologie, Sorbonne Université, Paris, France. ${ }^{18}$ APHP, Hôpital Saint-Louis, Centre MEARY de Thérapie Cellulaire et Génique, Paris, France. ${ }^{19}$ INSERM UMR1 140, Université de Paris, 75006 Paris, France. ${ }^{20}$ INSERM, UMR S 970, Paris Centre de Recherche Cardiovasculaire (PARCC), Université de Paris, Paris, France. ${ }^{21}$ Clinical Research Unit, Pitié-Salpêtrière University Hospital, APHP, Paris, France. ${ }^{22}$ Department of Cardiovascular Surgery, Hôpital Européen Georges-Pompidou, Paris, France. ${ }^{23}$ Multidisciplinary Intensive Care Unit, Department of Anesthesiology-Critical Care and Perioperative Medicine, Hôpital de la Pitié-Salpêtrière, 47-83, boulevard de l'Hôpital, 75651 Paris Cedex 13, France. ${ }^{24}$ Internal Use Pharmacy Department, REQPHARM Unit, La Pitié-Salpêtrière Hospital, Assistance Publique-Hôpitaux de Paris (APHP) Sorbonne University, Paris, France. ${ }^{25}$ Clinical Investigation Center (CIC) at La Pitié-Salpêtrière Hospital, Assistance Publique-Hôpitaux de Paris (APHP), Sorbonne University, Paris, France.

\section{Received: 31 October 2021 Accepted: 14 February 2022} Published online: 21 February 2022

\section{References}

1. COVID-ICU Group on behalf of the REVA Network and the COVID-ICU Investigators. Clinical characteristics and day-90 outcomes of 4244 critically ill adults with COVID-19: a prospective cohort study. Intensive Care Med. 2021;47:60-73.

2. Wiersinga WJ, Rhodes A, Cheng AC, Peacock SJ, Prescott HC. Pathophysiology, transmission, diagnosis, and treatment of coronavirus disease 2019 (COVID-19): a review. JAMA. 2020;324:782.

3. The WHO Rapid Evidence Appraisal for COVID-19 Therapies (REACT) Working Group, Sterne JAC, Murthy S, Diaz JV, Slutsky AS, Villar J, et al. Association Between Administration of Systemic Corticosteroids and Mortality Among Critically III Patients With COVID-19: A Meta-analysis. JAMA. 2020;324(13):1330-1341.

4. The REMAP-CAP Investigators. Interleukin-6 receptor antagonists in critically ill patients with Covid-19. N Engl J Med. 2021:384:1491-502.

5. Contou D, Fraissé M, Pajot O, Tirolien J-A, Mentec H, Plantefève G. Comparison between first and second wave among critically ill COVID-19 patients admitted to a French ICU: no prognostic improvement during the second wave? Crit Care. 2021;25:3.

6. Pittenger MF, Discher DE, Péault BM, Phinney DG, Hare JM, Caplan Al. Mesenchymal stem cell perspective: cell biology to clinical progress. npj Regen Med. 2019;4:22.

7. Squillaro T, Peluso G, Galderisi U. Clinical trials with mesenchymal stem cells: an update. Cell Transplant. 2016;25:829-48.

8. Xu Z, Huang Y, Zhou J, Deng X, He W, Liu X, et al. Current status of cellbased therapies for COVID-19: evidence from mesenchymal stromal cells in sepsis and ARDS. Front Immunol. 2021;12: 738697.

9. Ankrum JA, Ong JF, Karp JM. Mesenchymal stem cells: immune evasive, not immune privileged. Nat Biotechnol. 2014;32:252-60.
10. Thompson M, Mei SHJ, Wolfe D, Champagne J, Fergusson D, Stewart $D J$, et al. Cell therapy with intravascular administration of mesenchymal stromal cells continues to appear safe: an updated systematic review and meta-analysis. EClinicalMedicine. 2020;19: 100249.

11. Zhang Y, Ravikumar M, Ling L, Nurcombe V, Cool SM. Age-related changes in the inflammatory status of human mesenchymal stem cells: implications for cell therapy. Stem Cell Reports. 2021:16(4):694-707.

12. Wilson JG, Liu KD, Zhuo H, Caballero L, McMillan M, Fang X, et al. Mesenchymal stem (stromal) cells for treatment of ARDS: a phase 1 clinical trial. Lancet Respir Med. 2015;3:24-32.

13. Matthay MA, Calfee CS, Zhuo H, Thompson BT, Wilson JG, Levitt JE, et al. Treatment with allogeneic mesenchymal stromal cells for moderate to severe acute respiratory distress syndrome (START study): a randomised phase 2a safety trial. Lancet Respir Med. 2019;7(2):154-62.

14. Zheng G, Huang L, Tong H, Shu Q, Hu Y, Ge M, et al. Treatment of acute respiratory distress syndrome with allogeneic adipose-derived mesenchymal stem cells: a randomized, placebo-controlled pilot study. Respir Res. 2014;15:39.

15. Can A, Celikkan FT, Cinar O. Umbilical cord mesenchymal stromal cell transplantations: a systemic analysis of clinical trials. Cytotherapy. 2017;19(12):1351-82.

16. Amable PR, Teixeira MVT, Carias RBV, Granjeiro JM, Borojevic R. Protein synthesis and secretion in human mesenchymal cells derived from bone marrow, adipose tissue and Wharton's jelly. Stem Cell Res Ther. 2014;5:53.

17. Kehl D, Generali M, Mallone A, Heller M, Uldry A-C, Cheng P, et al. Proteomic analysis of human mesenchymal stromal cell secretomes: a systematic comparison of the angiogenic potential. NPJ Regen Med. 2019;16(4):8.

18. Liau LL, Ruszymah BHI, Ng MH, Law JX. Characteristics and clinical applications of Wharton's jelly-derived mesenchymal stromal cells. Curr Res Transl Med. 2020;68(1):5-16.

19. Xie Y, Chen F, Jia L, Chen R, Zhang VW, Zhong X, et al. Mesenchymal stem cells from different sources show distinct therapeutic effects in hyperoxia-induced bronchopulmonary dysplasia in rats. J Cell Mol Med. 2021:25:8558-66.

20. Ciccocioppo R, Gibellini D, Astori G, Bernardi M, Bozza A, Chieregato K, et al. The immune modulatory effects of umbilical cord-derived mesenchymal stromal cells in severe COVID-19 pneumonia. Stem Cell Res Ther. 2021;12:316.

21. Golchin A, Seyedjafari E, Ardeshirylajimi A. Mesenchymal stem cell therapy for COVID-19: present or future. Stem Cell Rev and Rep. 2020;16:427-33.

22. Leng Z, Zhu R, Hou W, Feng Y, Yang Y, Han Q, et al. Transplantation of ACE2- mesenchymal stem cells improves the outcome of patients with COVID-19 pneumonia. Aging Dis. 2020;11(2):216-28.

23. Desterke C, Griscelli F, Imeri J, Marcoux P, Lemonnier T, Latsis T, et al. Molecular investigation of adequate sources of mesenchymal stem cells for cell therapy of COVID-19-associated organ failure. Stem Cells Transl Med. 2021;10(4):568-71.

24. Liang B, Chen J, Li T, Wu H, Yang W, Li Y, et al. Clinical remission of a critically ill COVID-19 patient treated by human umbilical cord mesenchymal stem cells: a case report. Medicine (Baltimore). 2020;99(31): e21429.

25. Zhu Y, Zhu R, Liu K, Li X, Chen D, Bai D, et al. Human umbilical cord mesenchymal stem cells for adjuvant treatment of a critically ill COVID-19 patient: a case report. Infect Drug Resist. 2020;13:3295-300.

26. Tang L, Jiang Y, Zhu M, Chen L, Zhou X, Zhou C, et al. Clinical study using mesenchymal stem cells for the treatment of patients with severe COVID19. Front Med. 2020;14:664-73.

27. Meng F, Xu R, Wang S, Xu Z, Zhang C, Li Y, et al. Human umbilical cordderived mesenchymal stem cell therapy in patients with COVID-19: a phase 1 clinical trial. Sig Transduct Target Ther. 2020;5:172.

28. Guo Z, Chen Y, Luo X, He X, Zhang Y, Wang J. Administration of umbilical cord mesenchymal stem cells in patients with severe COVID-19 pneumonia. Crit Care. 2020;24:420.

29. Shu L, Niu C, Li R, Huang T, Wang Y, Huang M, et al. Treatment of severe COVID-19 with human umbilical cord mesenchymal stem cells. Stem Cell Res Ther. 2020;11(1):361.

30. Lanzoni G, Linetsky E, Correa D, Messinger Cayetano S, Alvarez RA, Kouroupis D, et al. Umbilical cord mesenchymal stem cells for COVID-19 acute respiratory distress syndrome: a double-blind, phase 1/2a, randomized controlled trial. Stem Cells Transl Med. 2021;10(5):660-73. 
31. Dilogo IH, Aditianingsih D, Sugiarto A, Burhan E, Damayanti T, Sitompul PA, et al. Umbilical cord mesenchymal stromal cells as critical COVID-19 adjuvant therapy: a randomized controlled trial. Stem Cells Transl Med. 2021;10(9):1279-87.

32. Alhazzani W, Møller MH, Arabi YM, Loeb M, Gong MN, Oczkowski S, et al. Surviving sepsis campaign: guidelines on the management of critically ill adults with coronavirus disease 2019 (COVID-19). Intensive Care Med. 2020;46(5):854-87.

33. Griffiths MJD, McAuley DF, Perkins GD, Barrett N, Blackwood B, Boyle $A$, et al. Guidelines on the management of acute respiratory distress syndrome. BMJ Open Respir Res. 2019;6: e000420.

34. Mebarki M, Iglicki N, Marigny C, Abadie C, Nicolet C, Churlaud G, et al. Development of a human umbilical cord-derived mesenchymal stromal cell-based advanced therapy medicinal product to treat immune and/or inflammatory diseases. Stem Cell Res Ther. 2021;12:571.

35. Ge J, Guo L, Wang S, Zhang Y, Cai T, Zhao RCH, et al. The size of mesenchymal stem cells is a significant cause of vascular obstructions and stroke. Stem Cell Rev Rep. 2014;10(2):295-303.

36. Leibacher J, Dauber K, Ehser S, Brixner V, Kollar K, Vogel A, et al. Human mesenchymal stromal cells undergo apoptosis and fragmentation after intravenous application in immune-competent mice. Cytotherapy. 2017;19:61-74.

37. de Witte SFH, Luk F, Sierra Parraga JM, Gargesha M, Merino A, Korevaar SS, et al. Immunomodulation by therapeutic mesenchymal stromal cells (MSC) is triggered through phagocytosis of MSC by monocytic cells: the fate of MSC post infusion. Stem Cells. 2018;36:602-15.

38. Ciurea SO, Cao K, Fernandez-Vina M, Kongtim P, Malki MA, Fuchs E, et al. The European Society for Blood and Marrow Transplantation (EBMT) consensus guidelines for the detection and treatment of donor-specific anti-HLA antibodies (DSA) in haploidentical hematopoietic cell transplantation. Bone Marrow Transplant. 2018;53(5):521-34.

39. Bartolucci J, Verdugo FJ, González PL, Larrea RE, Abarzua E, Goset C, et al. Safety and efficacy of the intravenous infusion of umbilical cord mesenchymal stem cells in patients with heart failure: a phase 1/2 randomized controlled trial (RIMECARD Trial [Randomized Clinical Trial of Intravenous Infusion Umbilical Cord Mesenchymal Stem Cells on Cardiopathy]). Circ Res. 2017;121:1192-204.

40. Hocine HR, Costa HE, Dam N, Giustiniani J, Palacios I, Loiseau P, et al. Minimizing the risk of allo-sensitization to optimize the benefit of allogeneic cardiac-derived stem/progenitor cells. Sci Rep. 2017;7:41125.

41. Karbing DS, Kjærgaard S, Smith BW, Espersen K, Allerød C, Andreassen S, et al. Variation in the $\mathrm{PaO}_{2} / \mathrm{FiO}_{2}$ ratio with $\mathrm{FiO}_{2}$ : mathematical and experimental description, and clinical relevance. Crit Care. 2007;11:R118.

42. Acute Respiratory Distress Syndrome Network. Ventilation with lower tidal volumes as compared with traditional tidal volumes for acute lung injury and the acute respiratory distress syndrome. N Engl J Med. 2000;342(18):1301-8.

43. El-Khatib MF, Jamaleddine GW. Clinical relevance of the $\mathrm{PaO}_{2} / \mathrm{FiO}_{2}$ ratio. Crit Care. 2008;12:407.

44. Rubenfeld GD, Abraham E. When is a negative phase II trial truly negative? Am J Respir Crit Care Med. 2008;178:554-5.

45. Wick KD, Leligdowicz A, Zhuo H, Ware LB, Matthay MA. Mesenchymal stromal cells reduce evidence of lung injury in patients with ARDS. JC Insight. 2021;6: e148983.

46. Wyles CC, Houdek MT, Wyles SP, Wagner ER, Behfar A, Sierra RJ. Differential cytotoxicity of corticosteroids on human mesenchymal stem cells. Clin Orthop Relat Res. 2015:473(3):1155-64.

47. Kabat M, Bobkov I, Kumar S, Grumet M. Trends in mesenchymal stem cell clinical trials 2004-2018: is efficacy optimal in a narrow dose range? Stem Cells Transl Med. 2020;9:17-27.

48. Khoury M, Cuenca J, Cruz FF, Figueroa FE, Rocco PRM, Weiss DJ. Current status of cell-based therapies for respiratory virus infections: applicability to COVID-19. Eur Respir J. 2020;55:2000858.

\section{Publisher's Note}

Springer Nature remains neutral with regard to jurisdictional claims in published maps and institutional affiliations.

Ready to submit your research? Choose BMC and benefit from:

- fast, convenient online submission

- thorough peer review by experienced researchers in your field

- rapid publication on acceptance

- support for research data, including large and complex data types

- gold Open Access which fosters wider collaboration and increased citations

- maximum visibility for your research: over $100 \mathrm{M}$ website views per year

At BMC, research is always in progress.

Learn more biomedcentral.com/submissions 